\title{
Visual evoked responses in chronic alcoholics
}

\author{
Y-W CHAN, JG McLEOD, RR TUCK, JC WALSH, PA FEARY \\ From the Department of Medicine, University of Sydney and Department of Neurology, Royal Prince Alfred \\ Hospital, Sydney, Australia
}

SUMMARY Visual evoked responses (VERs) were recorded on 52 chronic alcoholic patients without Wernicke-Korsakoff syndrome, 22 of whom had cerebellar ataxia, and eight chronic alcoholics with Wernicke-Korsakoff syndrome. Abnormal VERs were found in $23 \%$ of patients without and $37 \%$ of patients with Wernicke-Korsakoff syndrome. The main VER abnormalities of all the alcoholic groups were prolonged latency and reduced amplitude of the P100 component. Improvement followed a six month period of abstinence. VERs may be useful in the early detection of alcohol induced brain damage, and in following the progress of patients with the condition.

Lesions of the visual pathways are known to be present in some chronic alcoholics. ${ }^{12}$ However, little is known about the frequency of subclinical involvement of the visual pathway in patients with milder forms of alcohol-induced brain damage, or the capacity for recovery with prolonged abstinence.

The recording of visual evoked responses (VERs) is a sensitive technique for the detection of subclinical lesions of the visual system. ${ }^{34}$ Abnormal VERs have been reported in asymptomatic chronic alcoholics, ${ }^{56}$ but the number of patients studied has been small. Although the effects of acute withdrawal on visual evoked responses have been established, ${ }^{7}$ studies of the effects of prolonged abstinence have not been described.

We report a study of the VERs in 52 chronic alcoholics without Wernicke-Korsakoff syndrome, 24 of whom were followed up for 6 months, and in eight chronic alcoholics with Wernicke-Korsakoff syndrome. The aim of our study was to examine the incidence and nature of VER abnormalities in alcoholic patients with and without Wernicke-Korsakoff syndrome, and to evaluate the effect of abstinence from alcohol.

\section{Subjects and methods}

\section{Controls}

The control subjects were 42 male volunteers whose ages ranged from 22 to 76 years (mean 45.9 years). Informed consent, drinking, smoking and medical histories were obtained. Only healthy subjects who abstained or drank less

Address for reprint requests to: JG McLeod, Department of Medicine, University of Sydney, NSW 2006, Australia.

Received 30 April 1985 and in revised form 28 November 1985. Accepted 2 December 1985 than $20 \mathrm{~g} /$ day and were not on drug treatment were accepted for study.

Chronic alcoholics without Wernicke-Korsakoff syndrome The group consisted of 52 males who had a history of an alcohol consumption of 50 to $200 \mathrm{~g} /$ day for 10 to 30 years but who had no history or clinical features of WernickeKorsakoff syndrome. Ages ranged from 25 to 63 years (mean 47.4 years). Thirty-six patients smoked cigarettes, ranging from 10 to 70 per day (median 22). They were further divided into two groups; group I (30 patients; age 25-59, mean 43.5 years) had no evidence of cerebellar degeneration; group II (22 patients; age 27-63, mean 51.6 years) had truncal and gait ataxia compatible with alcoholic cerebellar degeneration. ${ }^{8}$

A minimum abstinent period of 2 weeks was required before VERs were recorded.

Chronic alcoholics with Wernicke-Korsakoff syndrome

The group consisted of eight alcoholic patients admitted to hospital in whom the clinical diagnosis of WernickeKorsakoff syndrome was confirmed by neurological assessment. Their ages ranged from 50 to 70 years (mean 60.8 years) and all were males. They had a drinking history ranging from 10 to 35 years with a daily intake of 50 to $250 \mathrm{~g}$. Five patients smoked cigarettes, ranging from 10 to 30 per day (median 15). The initial VER was performed within 14 to 30 days (mean 22 days) of admission to hospital during which time they were completely abstinent from alcohol.

\section{Ophthalmological examination}

Ophthalmological examination was conducted on all subjects prior to the recording of evoked responses. It included examination of the distant and near visual acuities (with and without corrective lenses), colour and stereoscopic vision, peripheral and central visual fields, eye movements, pupils and the fundus.

Patients with refractive errors were referred to ophthalmologists for corrective lenses before the VERs were performed. Those who had persistent abnormal distant (worse 
than $6 / 9$ with Snellen chart) or near (worse than N6 with Cuprox chart) visual acuities, defective peripheral and central visual fields, cataract, vitreous abnormalities or optic atrophy were not accepted for VER study.

The visual evoked responses (VERs)

The montage for VER recording consisted of a transverse chain of five active electrodes placed $5 \mathrm{~cm}$ above the inion and $5 \mathrm{~cm}$ apart on either side of the midline electrode. These were all referred to a mid-frontal electrode placed at $12 \mathrm{~cm}$ from the nasion. The ground electrode was placed at the submental position.

The subject sat facing a translucent screen which was $60 \mathrm{~cm}$ from the stimulated eye and subtended a visual angle of $32^{\circ} \mathrm{C}$. The stimulus consisted of a black and white checkerboard pattern which was back projected via a moveable mirror onto the screen, so that the individual squares subtended an angle of 55 minutes and the luminance levels were $0.8 \mathrm{~cd} / \mathrm{m}^{2}$ for the black checks and $40 \mathrm{~cd} / \mathrm{m}^{2}$ for the white checks respectively. Pattern reversal was produced once every $560 \mathrm{~ms}$ by a rapid displacement $(10 \mathrm{~ms})$ of the checkerboard pattern using the mirror reversal technique. The amplitude of the pattern displacement was adjusted to be equal to one square width. A small fixation point in the form of a red light emitting diode was provided at the centre of the screen and fixation of the subject during the averaging procedure was strictly supervised. Runs with poor fixation or lack of concentration were noted and repeated. All recordings were made monocularly with the non-stimulated eye covered by a pad.

The responses recorded were amplified by a Devices (UK) D100/D150 amplifying system with a bandwidth between $1 \mathrm{kHz}$ and $0.5 \mathrm{~Hz}$ and a sensitivity of $50 \mu \mathrm{V} / \mathrm{V}$ before averaging by a D200 Digitimer analyser which was triggered by the pattern reversal. The averaged response to 128 reversals was recorded for each run which was repeated at least once in order to ensure the reproducibility of the results. The peak latency of the major positive wave (the P100 component) was measured to the nearest one millisecond while the amplitude was measured from the preceding negative peak, or from the baseline if there was no obvious preceding negative peak. Half field stimulation was employed if the P100 component showed a bifid trough (PNP complex) or if its ampli- tude was so small that the wave could not be identified with certainty.

The criteria for defining an abnormal VER were: (a) Latency to the major positive peak (P100) greater than 2.5 standard deviations above the mean for control subjects, (b) An interocular latency difference for the P100 component greater than 2.5 standard deviations above the mean for control subjects. This criterion applied only to those patients in whom the absolute latency for both eyes was within the normal range, (c) An absent response, unilateral or bilateral.

\section{Follow up studies}

Of the 52 patients without Wernicke-Korsakoff syndrome, 24 were followed up with a second examination at 6 months after the first study. They were divided into two groups according to their drinking histories after the first test; a non abstinent group (16 patients) and an abstinent group (eight patients). Of the eight patients with Wernicke-Korsakoff syndrome, three were followed up for 6 months. Of these three patients who had a second examination performed, two remained abstinent and one resumed drinking before 6 months. The same procedures for VER recordings were repeated. A change of latency $10 \mathrm{~ms}$ was regarded as significant. ${ }^{9}$

Patients were instructed to exhale into an alcohol meter before the recordings to ensure that no tests were done under the influence of recent alcohol intake. ${ }^{10}$

\section{Statistics}

The data were stored in a disc using a VAX 780 minicomputer and were analysed by means of the Scientific Information Retrieval and Statistical Packages of Social Science (SPSS) software packages.

The non-paired $t$ test was used to compare the means between groups and the paired $t$ test to compare the initial and follow-up results in the alcoholic group. The differences between means was considered significant when $p<0.05$.

\section{Results}

\section{Controls}

The major positive peak (P100 component) was

Table 1 VER in control subjects and chronic alcoholics

\begin{tabular}{|c|c|c|c|c|}
\hline & \multirow[t]{2}{*}{ Controls } & \multicolumn{2}{|c|}{ Non-Wernicke-Korsakoff syndrome alcoholics } & \multirow{2}{*}{$\begin{array}{l}\text { Wernicke-Korsakoff } \\
\text { syndrome alcoholics }\end{array}$} \\
\hline & & $\boldsymbol{I}$ & II & \\
\hline $\begin{array}{l}\text { No. of male subjects } \\
\text { Age }\end{array}$ & 42 & 30 & 22 & 8 \\
\hline $\begin{array}{l}\text { Range } \\
\text { Mean } \\
\text { P100 component }\end{array}$ & $\begin{array}{l}22-76 \\
45 \cdot 9\end{array}$ & $\begin{array}{l}25-59 \\
43 \cdot 5\end{array}$ & $\begin{array}{l}27-63 \\
51 \cdot 6\end{array}$ & $\begin{array}{l}50-70 \\
60 \cdot 8\end{array}$ \\
\hline $\begin{array}{l}\text { Latency (ms) } \\
\text { Amplitude ( } \mu \mathrm{V}) \\
\text { ILD (ms) }\end{array}$ & $\begin{array}{r}97.2 \pm 3.3 \\
7.9 \pm 3.0 \\
1.9 \pm 1.9\end{array}$ & $\begin{array}{l}99.4 \pm 5.2 \\
p<0.05 \\
6.3 \pm 3.2 \\
p<0.05 \\
4.0 \pm 4.2 \\
p<0.05\end{array}$ & $\begin{array}{l}100.3 \pm 7.0 \\
p<0.05 \\
5.0 \pm 2.8 \\
p<0.0005 \\
2.5 \pm 2.5 \\
\text { NS }\end{array}$ & $\begin{array}{l}104.6 \pm 7 \cdot 1 \\
p<0.005 \\
3.7 \pm 1.3 \\
p<0.0005 \\
2.8 \pm 2.6 \\
\text { NS }\end{array}$ \\
\hline
\end{tabular}

Mean values are expressed with standard deviations.

NS = not significant $(p>0.05)$.

ILD $=$ interocular latency difference. 

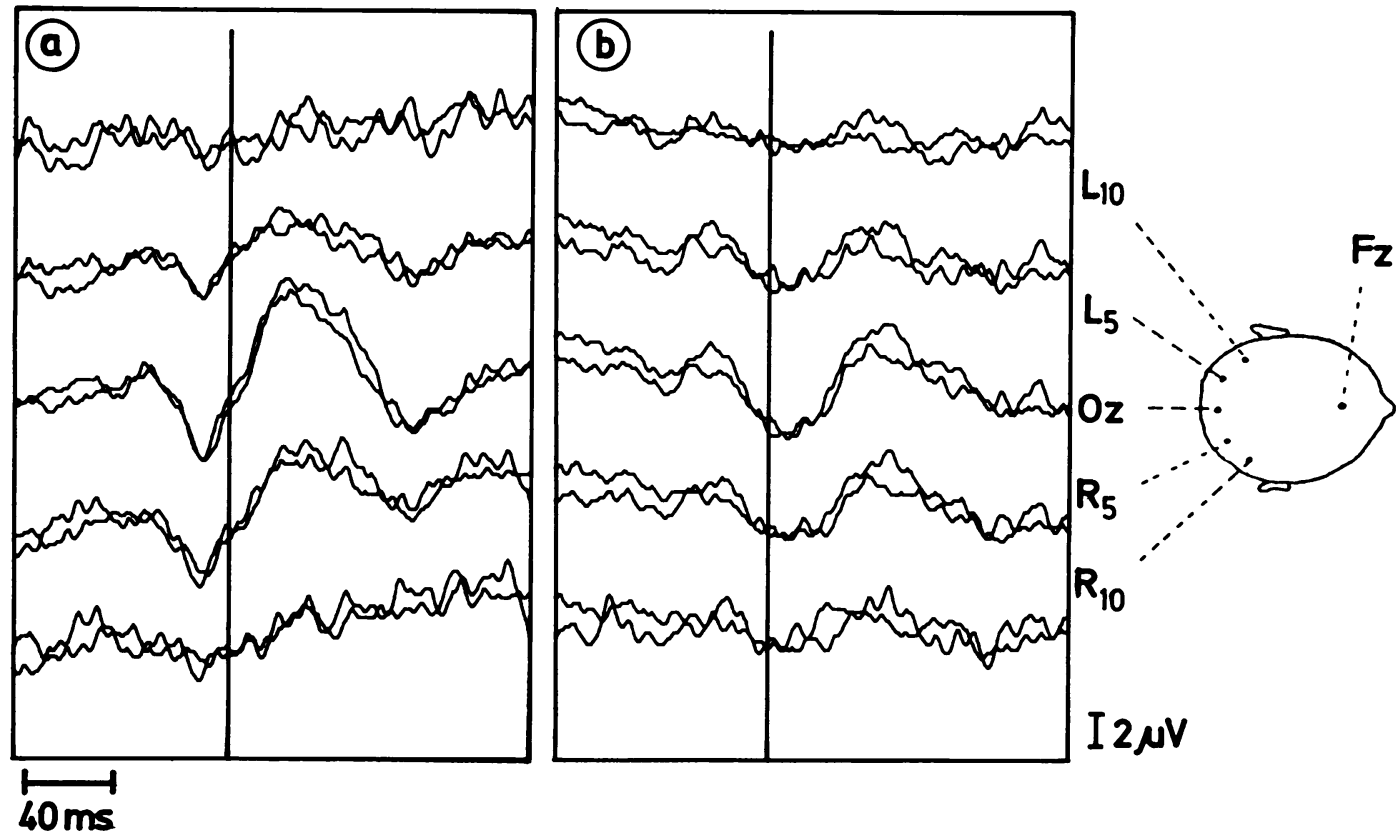

Fig 1 Pattern-reversal visual evoked responses to full field stimulation in a control subject (a) and a chronic alcoholic patient (b). Note the prolonged latency and reduced amplitude of the P100 component in B. Cursor indicates the upper limit of the normal P100 latency (106 ms).

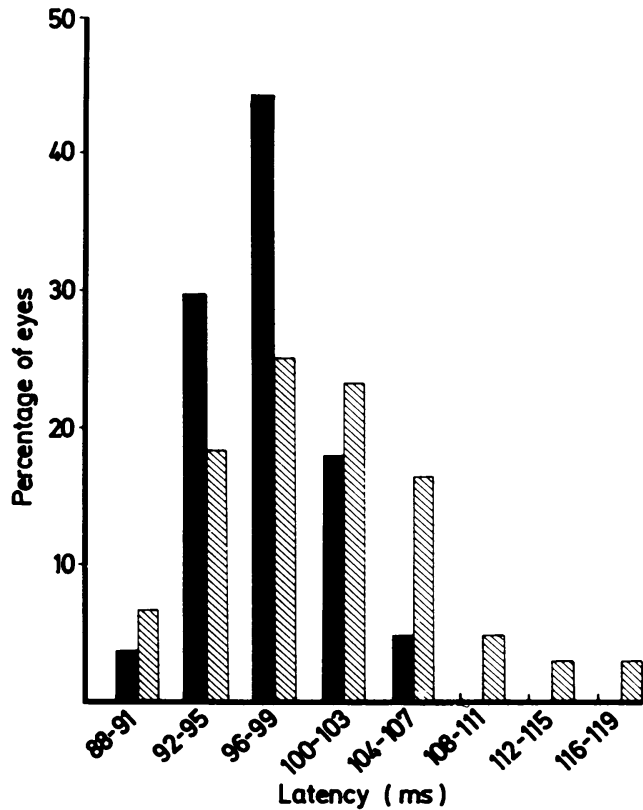

Fig 2 Distribution of values for P100 latency in control subjects (solid bars) and chronic alcoholics (hatched bars).

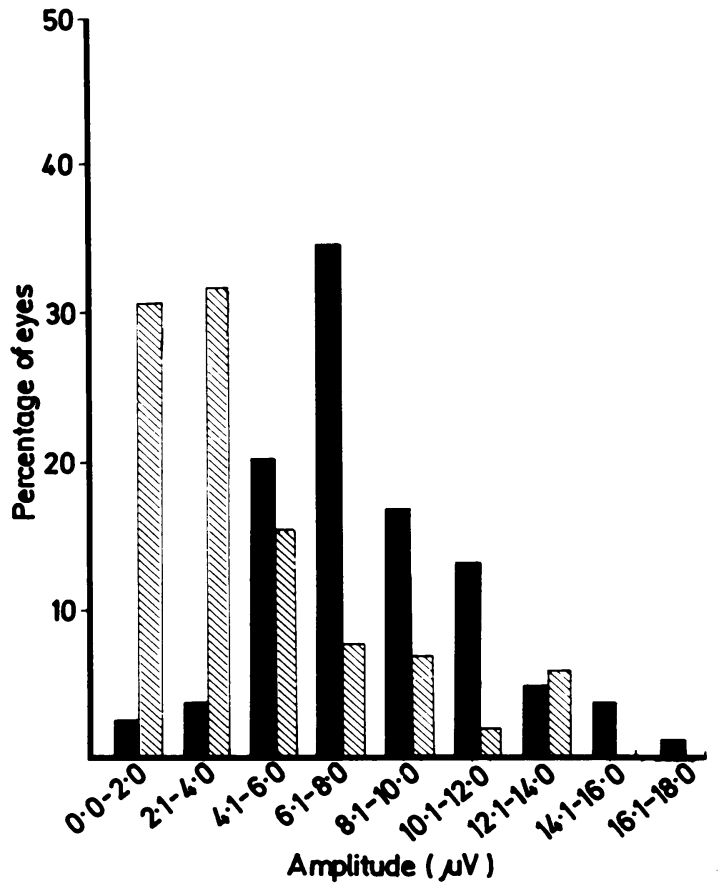

Fig 3 Distribution of values for P100 amplitude in control subjects (solid bars) and chronic alcoholics (hatched bars). 
Table 2 Types of VER abnormalities in subjects with and without Wernicke-Korsakoff syndrome

\begin{tabular}{|c|c|c|c|}
\hline & $\begin{array}{l}\text { Non-Wern } \\
I \\
n=30\end{array}$ & $\begin{array}{l}\text { me alcoholic } \\
\text { II } \\
n=22\end{array}$ & $\begin{array}{l}\text { Wernicke-Korsakoff syndrome } \\
\text { alcoholics } \\
n=8\end{array}$ \\
\hline $\begin{array}{l}\text { Normal VERs } \\
\text { Abnormal VERs } \\
\text { Bilateral } \\
\text { Unilateral } \\
\text { Types of P100 abnormalities } \\
\text { Prolonged latency (ms) } \\
\text { Prolonged ILD (ms) } \\
\text { Absent response }\end{array}$ & $\begin{array}{l}23 \\
7(23 \%) \\
0 \\
5 \\
5 \\
2 \\
0\end{array}$ & $\begin{array}{l}17 \\
5(23 \%) \\
2 \\
3 \\
5 \\
0 \\
0\end{array}$ & $\begin{array}{l}5 \\
3(37 \%) \\
3 \\
0 \\
3 \\
0 \\
0\end{array}$ \\
\hline
\end{tabular}

ILD = interocular latency difference

present in the VERs of all the controls. The mean $+2.5 \mathrm{SD}$ for the latency of the P100 component was $106 \mathrm{~ms}$ and for the interocular latency difference was $7 \mathrm{~ms}$ (table 1). There was no significant effect of age on the latency of the P100 component in the males.

\section{Chronic alcoholics}

The characteristic abnormality in all patient groups was a mild increase in latency and reduction in amplitude with a normal configuration of the response (fig. 1). Half-field stimulation, when performed, confirmed that the delayed response was P100. The distribution of the latency and amplitude of the P100 component in both control and patient groups is shown in figs 2 and 3.

\section{Chronic alcoholics without Wernicke-Korsakoff syndrome}

Of the 52 patients, $12(23 \%)$ had abnormal VERs. The patients were further divided into two groups:

Group I No evidence of cerebellar degeneration. Of the 30 patients, seven ( $23 \%$ ) had abnormal VERs. There were five patients with prolonged P100 component latencies and two with prolonged interocular latency differences. The increases in latency ranged

Table 3 Follow-up studies of non-Wernicke-Korsakoff syndrome alcoholic group

\begin{tabular}{lcc}
\hline & Ist Test & 2nd Test \\
\hline Non abstinent group & 16 & 16 \\
$\quad$ No of subjects & 15 & 13 \\
Normal VERs & 1 & 3 \\
Abnormal VERs & $98.6 \pm 6.5$ & $98.9 \pm 5 \cdot 7$ \\
P100 component & $6.1 \pm 3.5$ & $5.7 \pm 2.5$ \\
Latency (ms) & 8 & 8 \\
Amplitude & 7 & 8 \\
Abstinent group & 1 & 0 \\
$\quad$ No of subjects & $100.5 \pm 5 \cdot 7$ & $98.2 \pm 7.1$ \\
Normal VERs & $4.0 \pm 1.8$ & $5.0 \pm 1.7$ \\
Abnormal VERs & & \\
P100 component & Latency (ms) &
\end{tabular}

from $108 \mathrm{~ms}$ to $119 \mathrm{~ms}$. All of the abnormalities occurred unilaterally (table 2 ). There was significant prolongation of the latency $(\mathrm{p}<0.05)$ and reduction of the amplitude of the P100 component ( $p<0.05)$ for the whole group. The interocular latency difference was also significantly increased $(p<0.05)$ (table 1).

Group II Evidence of cerebellar degeneration.

Of the 22 patients, five $(23 \%)$ had abnormal VERs. All of the five patients had prolonged P100 component latencies which occurred unilaterally in three and bilaterally in two (table 2). The increases in latency ranged from 107 to $117 \mathrm{~ms}$. There was significant prolongation of the latency and reduction of the amplitude of the P100 component for the whole group ( $\mathrm{p}<0.05$ and $\mathrm{p}<0.0005$ respectively). However, the interocular latency difference was not increased $(p>0.05)$ (table 1$)$.

Chronic alcoholics with Wernicke-Korsakoff syndrome Of the eight patients, three $(37 \%)$ had abnormal VERs. All of the three patients had prolonged P100 component latencies bilaterally (table 2). The increases in latency ranged from $107 \mathrm{~ms}$ to $122 \mathrm{~ms}$. There was significant prolongation of the latency and reduction of the amplitude of the $\mathrm{P} 100$ component for the whole group ( $p<0.005$ and $p<0.0005$ respectively). The interocular latency difference was not increased $(p>0.05)($ table 1$)$.

\section{FOLLOW UPSTUDIES}

\section{Chronic alcoholics without Wernicke-Korsakoff syndrome (table 3)}

Non-abstinent group Of the 24 patients followed up for 6 months, 16 continued drinking. One of the 16 patients had abnormal VERs at the initial study, but three had abnormal VERs at the follow up study. Of the 32 eyes studied the latency decreased $(\geqslant 10 \mathrm{~ms})$ in two $(6 \cdot 3 \%)$ and increased $(\geqslant 10 \mathrm{~ms})$ in one $(3 \%)$. There was no significant change in the mean latency and amplitude of the P100 component between the two examinations. 
Abstinent group Of the 24 patients followed up for 6 months, eight remained abstinent from alcohol. The only patient with abnormal VERs at the initial study returned to normal at the follow up study. Of the 16 eyes studied the latency decreased $(\geqslant 10 \mathrm{~ms})$ in three $(18.6 \%)$ and did not increase in any eyes. However, there were no significant changes in the latency and amplitude of the P100 component between the initial and the follow up studies for the whole group.

Chronic alcoholics with Wernicke-Korsakoff syndrome The three patients with abnormal VERs were followed up with a second examination at 6 months. Of the four abnormal VERs (two pairs of eyes) in the two patients who were abstinent, two returned to normal (latency decreased $\geqslant 10 \mathrm{~ms}$ ) at the second study. The VERs of the third patient who continued drinking remained abnormal at the second study.

\section{Discussion}

The characteristic visual disorder associated with chronic alcoholism is alcohol amblyopia in which there is impairment of central vision. ${ }^{12}$ Abnormal VERs have been reported in alcoholics with this condition ${ }^{11-13}$ and also in patients who have no evidence of visual impairment. ${ }^{56}$

In the present study, the incidence of abnormal VERs in chronic alcoholics without a history of Wernicke-Korsakoff syndrome was 23\% (12 of 52 patients). This proportion is slightly greater than that reported by Posthuma and Visser $(15 \%)^{5}$ and Ahmed and Hines $(13 \%){ }^{6}$ The study also indicated that the incidence of VER abnormalities $(23 \%)$ was the same for patients with or without the complication of cerebellar degeneration and that the incidence was higher (37\%) in chronic alcoholics with a history of Wernicke-Korsakoff syndrome. Despite the small size of the abstinent group, the follow-up studies demonstrated that there was a general trend for the VERs to return to normal after ceasing alcohol consumption.

The main features of the VER abnormalities of all the alcoholic patient groups were prolonged mean latency and reduced amplitude of the P100 component. The mild increase in latency (the longest was $122 \mathrm{~ms}$ ) and the normal configuration of the response suggest that the abnormality was due to delay of the P100 component, rather than block in central macular derived fibres, with a persistent P135. This conclusion was supported by the results of half-field stimulation, when performed. The P100 component of the VER results mainly from the effect of foveal stimulation. ${ }^{14}$ Abnormalities of the P100 component therefore usually suggest a conduction defect in the optic fibres especially in those which are responsible for central vision. These VER findings are consistent with the pathological changes of alcohol amblyopia in which the papillo-macular bundles are affected. ${ }^{12}$ The fact that abnormal VERs were found in visually asymptomatic alcoholic patients suggests that there might be a subclinical form of alcohol amblyopia.

Although the incidence of abnormal VERs was similar for both Group I and II patients of the alcoholics without Wernicke-Korsakoff syndrome, the extent of the abnormalities was different. Patients with cerebellar degeneration had more bilateral VER abnormalities than patients without cerebellar degeneration. The lack of interocular latency difference of the P100 component in the former group suggests that the lesions are of a diffuse nature and may occur either prechiasmally or postchiasmally. By contrast, patients without cerebellar degeneration had only unilateral abnormalities suggesting that the lesions are predominantly unilateral, most likely occurring in the prechiasmal region at the optic nerves or the retina. In the classical description of the visual defect in alcohol amblyopia, Traquair ${ }^{15}$ reported that in the early stages one eye may be affected before a defect could be detected in the other. Although both eyes are usually affected symmetrically, asymmetrical fields, unilateral defects and asymmetrical pathological changes have been reported in the condition by other workers. ${ }^{16}$ It seems likely that Group I and II patients merely represent patients who are in different stages of the development of the disorder.

The pathogenesis of the conduction delay in the VER of chronic alcoholics remains uncertain. It may be a consequence of nutritional deficiency affecting the structure and function of the optic nerve, ${ }^{12}{ }^{17}$ or the effect of ethanol on neurotransmitter release ${ }^{18}$ or cerebral amine metabolism. ${ }^{1920}$ Whatever the mechanism, the finding of abnormal VERs in patients with alcohol-related brain damage suggests that they may be useful in the detection of early changes, and in following the progress of patients with the disorder.

The work was supported by a grant from the Australian Associated Brewers. Dr Chan was supported by the Bushell Trust, and the Sir Robert Black Trust, Hong Kong.

\section{References}

${ }^{1}$ Victor MA, Mancall EL, Dreyfus PM. Deficiency amblyopia in the alcoholic patient. A clinicopathologic study. Arch Ophthalmol 1960;67:1-20.

${ }^{2}$ Victor MA, Dreyfus PM. Tobacco-alcohol amblyopiafurther comments on its pathology. Arch Ophthalmol 1965;74:649-57.

${ }^{3}$ Halliday AM, McDonald WI, Mushin J. Delayed visual evoked responses in optic neuritis. Lancet 1972;1:982-5. 
${ }^{4}$ Halliday AM, McDonald WI, Mushin J. The visual evoked responses in the diagnosis of multiple sclerosis. Br Med J 1973;4:661-4.

${ }^{5}$ Posthuma J, Visser SL. Visual evoked potentials and alcohol induced brain damage. In: Courjon $\mathbf{J}$, Mauguière $\mathbf{P}$, Revol M, eds. Clinical Applications of Evoked Potentials in Neurology. New York: Raven Press 1982:149-55.

${ }^{6}$ Ahmed I, Hines KS. Visual evoked potentials in alcoholics. Clin Electroencephalogr 1983;14(1):17-19.

${ }^{7}$ Porjesz B, Begleiter H. Human evoked brain potentials and alcohol. Alcoholism; Clinical and Experimental Research 1981;5(2):304-17.

${ }^{8}$ Victor MA, Adams RD, Mancall EL. A restricted form of cerebellar cortical degeneration occurring in alcoholic patients. Arch Neurol 1959;1:579-688.

${ }^{9}$ Stockard JJ, Hughes HF, Sharbrough FW. Visually evoked potentials to electronic pattern reversal: latency variations with gender, age and technical factors. Am J EEG Technology 1979;19:171-204.

${ }^{10}$ Church MW, William HL. Dose and time related effects of ethanol on brain stem evoked responses in young adult males. Electroencephalogr Clin Neurophysiol 1982;54:161-74.

${ }^{11}$ Ikeda A, Tremain K, Sanders MD. Neurophysiological investigation in optic nerve disease: combined assessment of the visual evoked response and electroretinogram. Br J Ophthalmol 1978;62:227-39.

${ }^{12}$ Kriss A, Carrol WM, Blumhardt LD, Halliday AM. Pattern and flash evoked potential changes in toxic (nutritional) optic neuropathy. In: Courjon J, Maguière F, Revol M, eds. Clinical Application of Evoked Potentials in Neurology. New York: Raven
Press 1982:11-19.

${ }^{13}$ Kupersmith MJ, Weiss PA, Carl RE. The visual evoked potential in tobacco-alcohol and nutritional amblyopia. Am J Ophthalmol 1983;95:307-14.

${ }^{14}$ Blumhardt LD, Barrett G. The effect of experimental 'scotomata' on the ipsilateral and contralateral responses to pattern-reversal in one half field. Electroencephalogr Clin Neurophysiology 1978;45:376-92.

${ }^{15}$ Traquair HM. An introduction to Clinical Perimetry: Tobacco Amblyopia, 3rd ed 1940:141-54. St Louis: The CV Mosby Company.

${ }^{16}$ Walsh FR, Hoyt WB. Clinical Neuroophthalmology, 3rd ed, Vol 3. Baltimore: Williams and Wilkins 1969: 2613-4.

${ }^{17}$ Dreyfus PM. Amblyopia and other neurological disorders associated with chronic alcoholism. In: Vinken PJ, Bruyn GW, eds. Handbook of Clinical Neurology. Vol 28, Part II. Metabolic and Deficiency Disease of the Nervous System. Amsterdam: Elsevier North Holland Inc 1976:231-347.

${ }^{18}$ Littlejohn JM, John GR, Jones PA, Grieve SJ. The rapid onset of functional tolerance to ethanol-role of different neurotransmitters and synaptosomal membrane lipids. Acta Psychiatr Scand (suppl) 1980;286:137-51.

${ }^{19}$ Reggiani A, Barbaccia ML, Spano PF, Trabucchi M. Dopamine metabolism and receptor function after acute and chronic ethanol consumption. $J$ Neurochem 1980;35(1):34-37.

${ }^{20}$ Schafer WP, McKean CM. Evidence that monamines influence human evoked potentials. Brain Res 1975; 99:49-58. 